\title{
Així escriuen els químics, encara que no tinguin llapis ni bolígraf...
}

\author{
Josep Corominas Viñas (jcoromi6@xtec.cat).Departament de Ciències. Escola Pia de Sitges, Sitges
}

Aquest article explica un treball pràctic de química que consisteix en una electròlisi de substàncies iòniques, presentat en un aspecte lúdic. L'activitat pràctica pot presentar-se com a una activitat POE (Predicció-Observació-Explicació), per a estudiants de química de batxillerat $i$ com un aspecte de la interacció entre matèria (substàncies iòniques) $i$ energia (corrent elèctric) per estudiants d'ESO. Per altra part l'observació dels canvis de colors dels indicadors àcid-base, permet ajuntar els conceptes de reacció redox amb la detecció de medis àcids i bàsics

Paraules clau: electròlisi; reaccions d'oxidació-reducció; FEM, potencials de reducció; indicadors àcid base

This article explains a practical work of chemistry, presented in a playful way, which consists on the electrolysis of ionic substances. This practical activity can be realised as a POE (Prediction-observation - explanation) activity for high school chemistry students, and focusing on the interaction between matter (ionic substances) and energy (electric current) for compulsory science students. Moreover, the observation of colour changes in acidbase indicators, allows the link between the concepts of redox reaction with acidic and basic media detection.

Key words: electrolysis; redox reactions, EFM, electrode potentials, acid-base indicators

\section{INTRODUCCIÓ}

$\mathrm{Hi}$ ha ocasions en les quals les reaccions químiques es presenten sota un aspecte lúdic, la veritable finalitat no és el pur entreteniment si no el centrar l'atenció del públic en el comportament i en les propietats químiques de la substàncies $\mathrm{i}$ materials. L'aproximació sota l'aspecte recreatiu, de vegades "màgic", és una metodologia per atreure l'atenció, impressionar de vegades, i crear l'oportunitat de fer reflexionar científicament (Shakhashiri, B. 1983)

Les reaccions químiques de canvis de color, sigui per oxidació-reducció, per formació de complexos o pels canvis d'un indicador segons el $\mathrm{pH}$ del mitjà són les que millor es presten a una dramatització (Corominas, J. 2011)

\section{JUSTIFICACIÓ DE L’EXPERIMENT PROPOSAT}

El pas de corrent elèctric a traves d'una solució que conté ions és un dels conceptes importants en química tant a nivell d'ESO com a batxillerat.

A I'ESO cal enfocar-lo com el cas de canvi químic en el qual les substàncies inicials, sòlids solubles en aigua, quan estan en solució condueixen el corrent, observant-se canvis per formació de noves substàncies.

A la química de batxillerat, l'electròlisi cal tractar-la com una reacció redox, discutint a partir dels potencials de reducció el per què es formen unes substàncies i no altres.

L'electròlisi és un important procés industrial, que permet per exemple obtenir productes d'ampli ús com el clor i els seus derivats o evitar la corrosió de metalls mitjançant els recobriments electrolítics. 


\section{COM PRESENTAR L'EXPERIMENT?}

L'aspecte més lúdic i purament descriptiu es reserva per cursos inicials de ciències $o$ per el públic en general: simplement és tracta d'observar com el pas de corrent elèctric, provoca canvis visibles.

Per nivells d'estudiants de química inicials ( 3 ESO o 4 ESO), és necessari fixar l'atenció en els següents punts:

- Usem unes substàncies iòniques, que són molt solubles en aigua

- El pas de corrent elèctric, provoca reaccions químiques que detectem per canvis de color dels indicadors

- És important observar en quin elèctrode es produeix el canvi de color, cosa que ens donarà una pista per esbrinar la càrrega dels ions que intervenen.

Els estudiants de química de batxillerat, treballaran aquest experiment, després d'haver vist els conceptes d'indicadors àcid-base, de reaccions redox, d'electròlisi i de FEM; de manera que abans d'observar l'experiment puguin raonar què s'espera que passarà. En aquest cas el professor plantejarà la situació de la següent manera:

- Disposem de dos elèctrodes: un d'ells és una safata d'alumini i l'altre és un simple cable de connexió. Mullarem un paper que estarà en contacte amb la safata amb una solució de clorur de sodi, i posteriorment amb iodur de potassi, en connectar els dos elèctrodes, quins fenòmens esperem que passin? Quins productes esperem que s'obtinguin en cada un dels elèctrodes?

- Per què malgrat la presència d'ions sodi $\mathrm{i}$ potassi en les respectives solucions, no obtenim els corresponents metalls?

- De quina manera fàcil podem posar en evidència la formació de medi bàsic en l'electròlisi d'aquestes sals?

\section{ESCRIURE EN COLOR VERMELL, BLAU I VERD}

\section{Procediment}

1) Dissoldre una cullerada de sal de cuina (clorur de sodi, $\mathrm{NaCl}$ ) en un vas amb aigua.

2) Afegir a la solució de sal, unes 10 gotes de la solució del indicador fenolftaleïna. Remenar

3) Posar el paper en el fons de la safata d'alumini. Si cal es retalla de manera que ajusti bé.
4) Mullar bé el paper amb la solució de sal i fenolftaleïna, sense que quedi cap excés de líquid per sobre del paper.

5) Connectar els cables a la font d'alimentació. EI cable del pol positiu (color vermell) es connecta a la safata d'alumini, amb la pinça de cocodril. El cable del pol negatiu (color negre) es deixa lliure sense cap contacte.

6) Es regula el voltatge a $9 \mathrm{~V}$ de corrent continu. Si no es disposa de font d'alimentació dues piles de 4,5 V, en sèrie fan la mateixa funció.

7) Per escriure: es passa amb suavitat el terminal lliure, connectat al pol negatiu de la font d'alimentació per el paper.

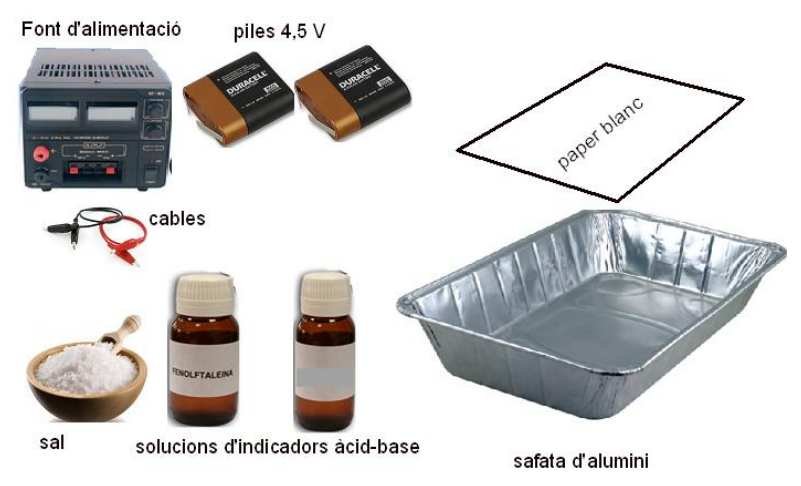

Figura 1. Materials per escriure en color vermell, blau i verd.

\section{Explicació}

S'està fent una electròlisi d'una solució aquosa de clorur de sodi. Les reaccions són:

càtode (-) : $2 \mathrm{H}_{2} \mathrm{O}(\mathrm{l})+2 \mathrm{e}^{-} \rightarrow \mathrm{H}_{2}(\mathrm{~g})+2 \mathrm{OH}^{-}(\mathrm{aq})$

ànode $(+): 2 \mathrm{Cl}^{-}(\mathrm{aq}) \rightarrow 2 \mathrm{Cl}_{2}(\mathrm{~g})+2 \mathrm{e}^{-}$

reacció iònica global:

$2 \mathrm{H}_{2} \mathrm{O}(\mathrm{l})+2 \mathrm{Cl}^{-}(\mathrm{aq}) \rightarrow 2 \mathrm{Cl}_{2}(\mathrm{~g})+\mathrm{H}_{2}(\mathrm{~g})+2 \mathrm{OH}^{-}(\mathrm{aq})$

Els ions $\mathrm{OH}^{-}$que es formen en el càtode, que és el terminal lliure que es passa per damunt del paper, són els responsables que l'indicador fenolftaleïna, agafi el color vermell del medi bàsic.

Com es pot veure, els ions sodi, $\mathrm{Na}^{+}$no es redueixen, ja que resulta que el potencial estàndard de reducció de l'ió $\mathrm{Na}^{+}$és molt més negatiu que el potencial de reducció de l'aigua a hidrogen $(E=-$ $0,42 \mathrm{~V}$ ). Per tant, serà l'aigua qui es reduirà en el càtode i no els ions $\mathrm{Na}^{+}$.

$$
\mathrm{Na}^{+}(\mathrm{aq})+\mathrm{e}^{-} \rightarrow \mathrm{Na}(\mathrm{s}) \quad \mathrm{E}^{\circ}=-2,71 \mathrm{~V}
$$




\section{ESCRIURE EN COLOR BLAU}

Tot igual, però amb l'indicador blau de bromotimol. En aquest cas, el indicador és blau en medi bàsic.

\section{ESCRIURE EN COLOR VERD}

Igual però amb l'indicador suc de col vermella El suc de col vermella conté els pigments antocianines i flavonols. La mescla d'aquest $s$ pigments agafa colors verds a $\mathrm{pH}$ entre $10 \mathrm{i} 12 \mathrm{i}$ grocs a pH de 13 i superiors

\section{ESCRIURE EN COLOR NEGRE}

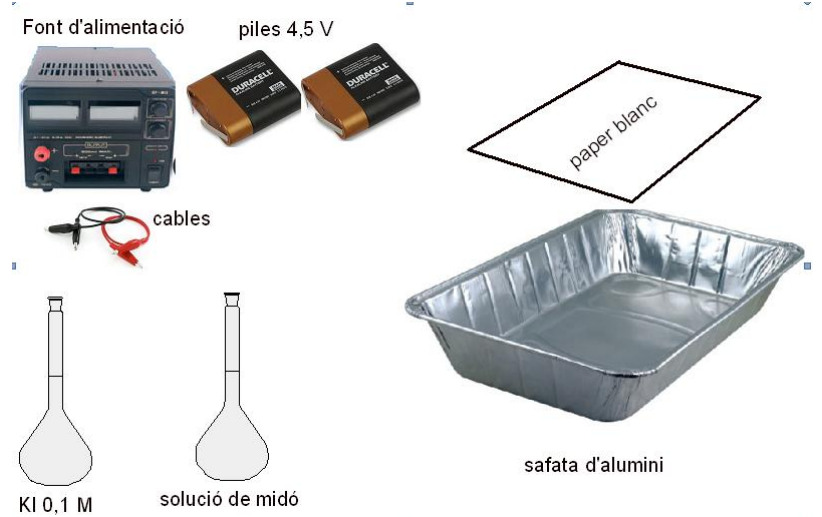

Figura 2. Materials per escriure en color negre.

\section{Procediment}

1) Posar el paper en el fons de la safata d'alumini. Si cal es retalla de manera que ajusti bé.

2) Barrejar $20 \mathrm{~mL}$ de solució de iodur de potassi $0,1 \mathrm{M}$ amb $10 \mathrm{~mL}$ de solució de midó en un vas de precipitats o qualsevol recipient. Remenar.

3) Mullar bé el paper amb la solució de iodur de potassi i midó, sense que quedi cap excés de líquid per sobre del paper.

4) Connectar els cables a la font d'alimentació. El cable del pol negatiu (color negre) es connecta a la safata d'alumini, amb la pinça de cocodril. El cable del pol positiu (color vermell) es deixa lliure sense cap contacte.

5) Es regula el voltatge a $9 \mathrm{~V}$ de corrent continu. Si no es disposa de font d'alimentació dues piles de 4,5 V, en sèrie fan la mateixa funció.

6) Per escriure: es passa amb suavitat el terminal lliure, connectat al pol positiu de la font d'alimentació per el paper.

\section{Explicació}

S'està fent una electròlisi d'una solució aquosa de iodur de potassi. Les reaccions són:

Càtode: $2 \mathrm{H} 2 \mathrm{O}(\mathrm{l})+2 \mathrm{e}-\rightarrow \mathrm{H} 2(\mathrm{~g})+2 \mathrm{OH}-(\mathrm{aq})$

Ànode: $2 \mathrm{l}-(\mathrm{aq}) \rightarrow 2 \mathrm{e}-+\mathrm{I} 2(\mathrm{aq})$

El iode, $\mathrm{I}_{2}$ forma un complex de color blau molt fosc quasi negre amb el midó.

Els ions potassi, $\mathrm{K}^{+}$no es redueixen, ja que resulta que el potencial estàndard de reducció de l'ió $\mathrm{K}^{+}$és molt més negatiu que el potencial de reducció de l'aigua a hidrogen $(E=-0,42 \mathrm{~V})$. Per tant, serà l'aigua qui es reduirà en el càtode i no els ions $\mathrm{K}^{+}$.

$$
\mathrm{K}^{+}(\mathrm{aq})+\mathrm{e}^{-} \rightarrow \mathrm{K}(\mathrm{s}) \quad \mathrm{E}^{\circ}=-2,93 \mathrm{~V}
$$

\section{Preparació de les solucions}

La solució de iodur de potassi $0,1 \mathrm{M}$ es prepara dissolent $1,7 \mathrm{~g}$ de $\mathrm{KI}$ fins a $100 \mathrm{~mL}$ d'aigua destil.lada.

La solució del indicador fet amb suc de col vermella es prepara amb tres o quatre fulles de col vermella (anomenada "col llombarda"). Es tallen a trossos petits i es submergeixen en mig litre d'aigua molt calenta, sense que arribi a bullir durant uns 15 minuts. Es deixa refredar i es decanta el líquid que ha de quedar d'un color vermell o violat, segons el $\mathrm{pH}$ de l'aigua emprada. No és necessari emprar aigua destil.lada.

Les solucions dels indicadors fenolftaleïna, blau de bromotimol o altres, es venen ja preparades.

La solució de midó es prepara amb $2 \mathrm{~g}$ de midó soluble (podeu usar el que es ven per la cuina) que es barregen amb $30 \mathrm{~mL}$ d'aigua fins a formar una pasta. Després el conjunt es dissolt en un litre d'aigua.

\section{Canvis de color dels indicadors àcid- base per emprar en aquest experiment}

\begin{tabular}{|c|l|c|c|c|}
\hline Indicador & $\mathbf{p K a}$ & $\begin{array}{c}\text { Interval } \\
\text { efectiu de pH }\end{array}$ & forma àcida & $\begin{array}{c}\text { color } \\
\text { forma } \\
\text { bàsica }\end{array}$ \\
\hline $\begin{array}{c}\text { blau de bromotimol } \\
\text { fenolftaleïna }\end{array}$ & 7,1 & $6,0-7,8$ & incolor & $\begin{array}{c}\text { blau } \\
\text { vermell }\end{array}$ \\
\hline
\end{tabular}


El suc de col vermella agafa colors vermells $i$ violats a $\mathrm{pH}$ inferiors a $7 \mathrm{i}$ colors blaus i verds a $\mathrm{pH}$ entre 8,0 i 9,0. Per $\mathrm{pH}$ superior a 12,0 és de color groc.

\section{ASPECTES DE SEGURETAT}

a) La solució de fenolftaleïna és inflamable i s'ha de mantenir allunyada de qualsevol flama o font de calor intensa.

b) El voltatge de $9 \mathrm{~V}$ no presenta cap perill. La safata d'alumini i els elèctrodes poden tocarse sense problema.

\section{FONTS BIBLIOGRÀFIQUES}

SHAKHASHIRI B. Z. (1983) Chemical Demonstrations. A Handbook for Teachers of Chemistry. Madison, Wisconsin. The University of Winsconsin Press.

COROMINAS, JOSEP (2011) "Fiesta química: licores que no lo son, bebidas que no hay que beber y alguna cosa de comer" Revista Eureka sobre Enseñanza y Divulgación de las Ciencias 8, (article en línia) 454-459. (data de consulta 5 d'abril 2013) 